\title{
BMJ Open Association of seasonal viral acute respiratory infection with pneumococcal disease: a systematic review of population-based studies
}

\author{
You Li, Meagan E Peterson, Harry Campbell, Harish Nair
}

To cite: Li Y, Peterson ME, Campbell $\mathrm{H}$, et al. Association of seasonal viral acute respiratory infection with pneumococcal disease: a systematic review of populationbased studies. BMJ Open 2018;8:e019743. doi:10.1136/ bmjopen-2017-019743

- Prepublication history and additional material for this paper are available online. To view these files, please visit the journal online (http://dx.doi org/10.1136/bmjopen-2017019743).

Received 22 September 2017 Revised 8 March 2018 Accepted 21 March 2018
Check for updates

Centre for Global Health Research, Usher Institute of Population Health Sciences and Informatics, University of Edinburgh, Edinburgh, UK

Correspondence to You Li; You.Li2@ed.ac.uk

\section{ABSTRACT}

Objective Animal and in vitro studies suggest that viral acute respiratory infection (VARI) can predispose to pneumococcal infection. These findings suggest that the prevention of VARI can yield additional benefits for the control of pneumococcal disease (PD). In population-based studies, however, the evidence is not in accordance, possibly due to a variety of methodological challenges and problems in these studies. We aimed to summarise and critically review the methods and results from these studies in order to inform future studies.

Methods We conducted a systematic review of population-based studies that analysed the association between preceding seasonal VARI and subsequent PD. We searched MEDLINE, Embase and Global Health databases using tailored search strategies.

Results A total of 28 studies were included. After critically reviewing the methodologies and findings, 11 studies did not control for seasonal factors shared by VARI and PD. This, in turn, could lead to an overestimation of the association between the two illnesses. One case-control study was limited by its small sample size ( $\mathrm{n}$ case $=13$ ). The remaining 16 studies that controlled for seasonal factors suggested that influenza and/or respiratory syncytial virus (RSV) infections were likely to be associated with the subsequent occurrence of PD (influenza: 12/14 studies; RSV: 4/5 studies). However, these 16 studies were unable to conduct individual patient data-based analyses. Nevertheless, these studies suggested the association between VARI and subsequent PD was related to additional factors such as virus type and subtype, age group, comorbidity status, presentation of PD and pneumococcal serotype.

Conclusions Population-based studies do not give consistent support for an association between preceding seasonal VARI and subsequent PD incidence. The main methodological challenges of existing studies include the failure to use individual patient data, control for seasonal factors of VARI and PD, or include other factors related to the association (eg, virus, age, comorbidity and pneumococcal serotype).

\section{INTRODUCTION}

Both viral acute respiratory infection (VARI) and pneumococcal disease (PD) account for a substantial disease burden

\section{Strengths and limitations of this study}

- This is the first review that critically reviewed the methods and findings of population-based studies that reported an association between viral acute respiratory infection and pneumococcal disease.

- Results of studies summarised according to study design and methods.

- No meta-analysis was conducted due to a variety of study designs, data sources and analytical methods in the studies so a narrative summary of the methods and results is provided.

worldwide, especially in young children and the elderly. ${ }^{1-3}$ The association of VARI and subsequent PD was not well recognised until the catastrophic 1918 influenza pandemic, which resulted in an estimated 40-50 million deaths ${ }^{4}$; it has been suggested that pneumococcus may have been a major cause of death. ${ }^{5}$ Most recently, it was observed that the incidence of PD was higher during 2009 influenza H1N1 pandemic period than the same period in prepandemic ${ }^{6-10}$ and postpandemic years. ${ }^{7910}$

During interpandemic periods, the associations of seasonal influenza and other seasonal respiratory viruses such as respiratory syncytial virus (RSV), human metapneumovirus and parainfluenza virus (PIV) with PD incidence are poorly understood and remain unclear. In animal and in vitro studies, it has been suggested that viral respiratory infection could predispose to pneumococcal infection and might facilitate pneumococcal transmission; in turn, this coinfection could induce a lethal synergism that is much more severe than infection with either pathogen alone (a brief summary of findings is displayed in online supplementary Table S1). However, these studies are all relatively small-scale studies and may be subject to publication bias favouring reporting of positive findings. In 


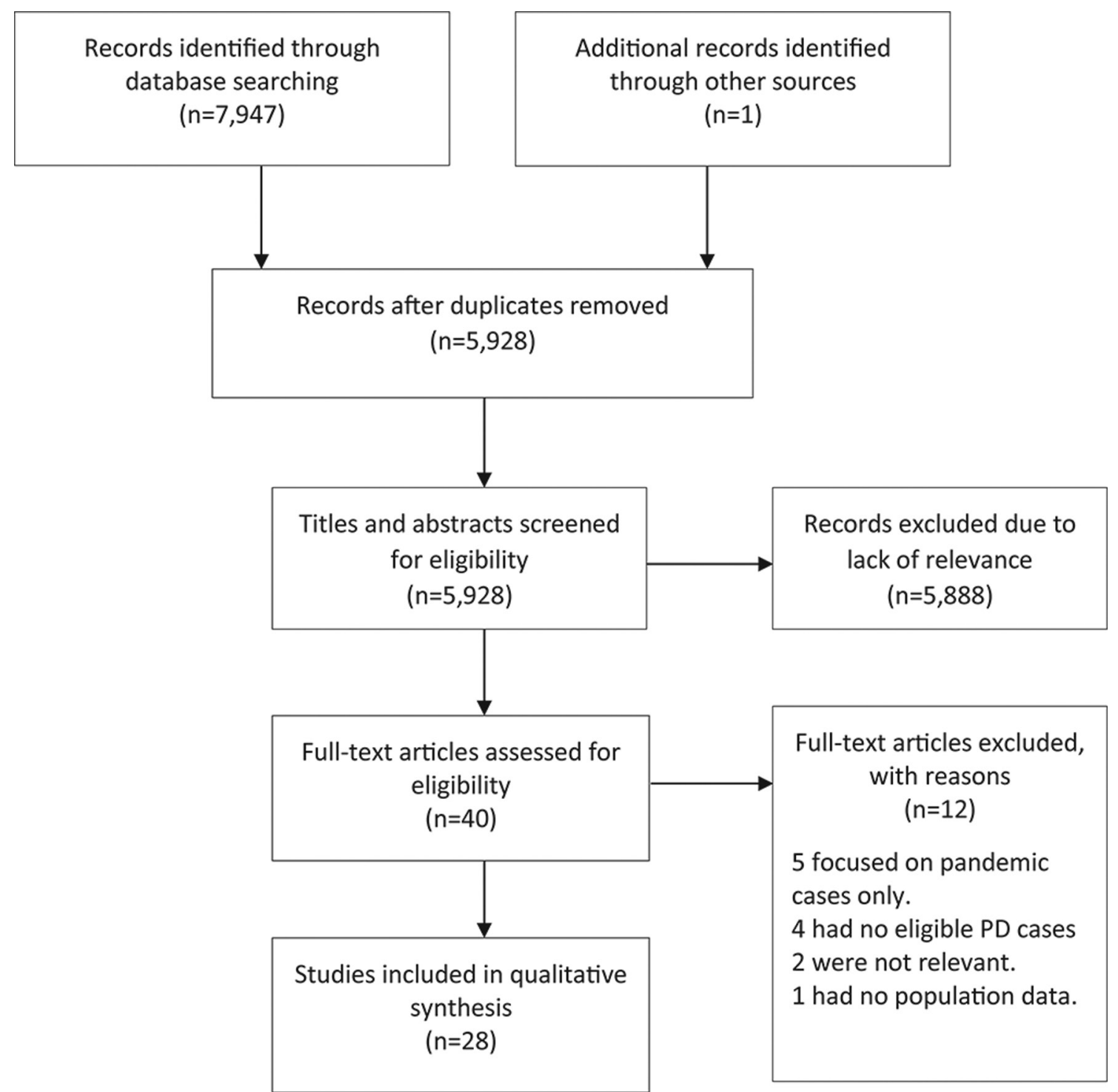

Figure 1 Preferred Reporting Items for Systematic Reviews and Meta-Analyses flow diagram of the literature search. PD, pneumococcal disease.

population-based studies, the findings were inconsistent. These studies differed substantially in study design, data sources and methods, making it difficult to compare and interpret the results across the studies. We conducted a systematic review of population-based studies on the association of preceding VARI on the occurrence of PD to summarise the methodology and results, critically review the findings and present recommendations for future studies.

\section{METHODS}

\section{Search strategy and selection criteria}

We searched MEDLINE, Embase and Global Health databases using tailored search strategies (search strategies in online supplementary Text S1, Preferred Reporting Items for Systematic Reviews and Meta-Analyses (PRISMA) flow chart in figure 1). We restricted the search to studies published between 1 January 1990 and 31 December 2017. We included population-based studies with clinically diagnosed PD cases (see next for detailed definition). In terms of VARI exposure, we accepted the following studies: (1) those with laboratory-confirmed viral infections; (2) those with the Internation Classification of Diseases (ICD) code for influenza and/or RSV infection and (3) those with case definition of influenza-like illness (ILI) and bronchiolitis as proxies for influenza and RSV, respectively. We excluded animal studies and theoretical studies where no population data were applied. We focused our review on the association of seasonal VARI and PD and thus excluded studies that reported pandemic influenza cases only. No language restrictions were applied. The reference lists of eligible studies were also checked to identify additional studies for inclusion. For all included studies, quality assessment was conducted using tailored Critical Appraisal Skills Programme checklists for case-control studies and 


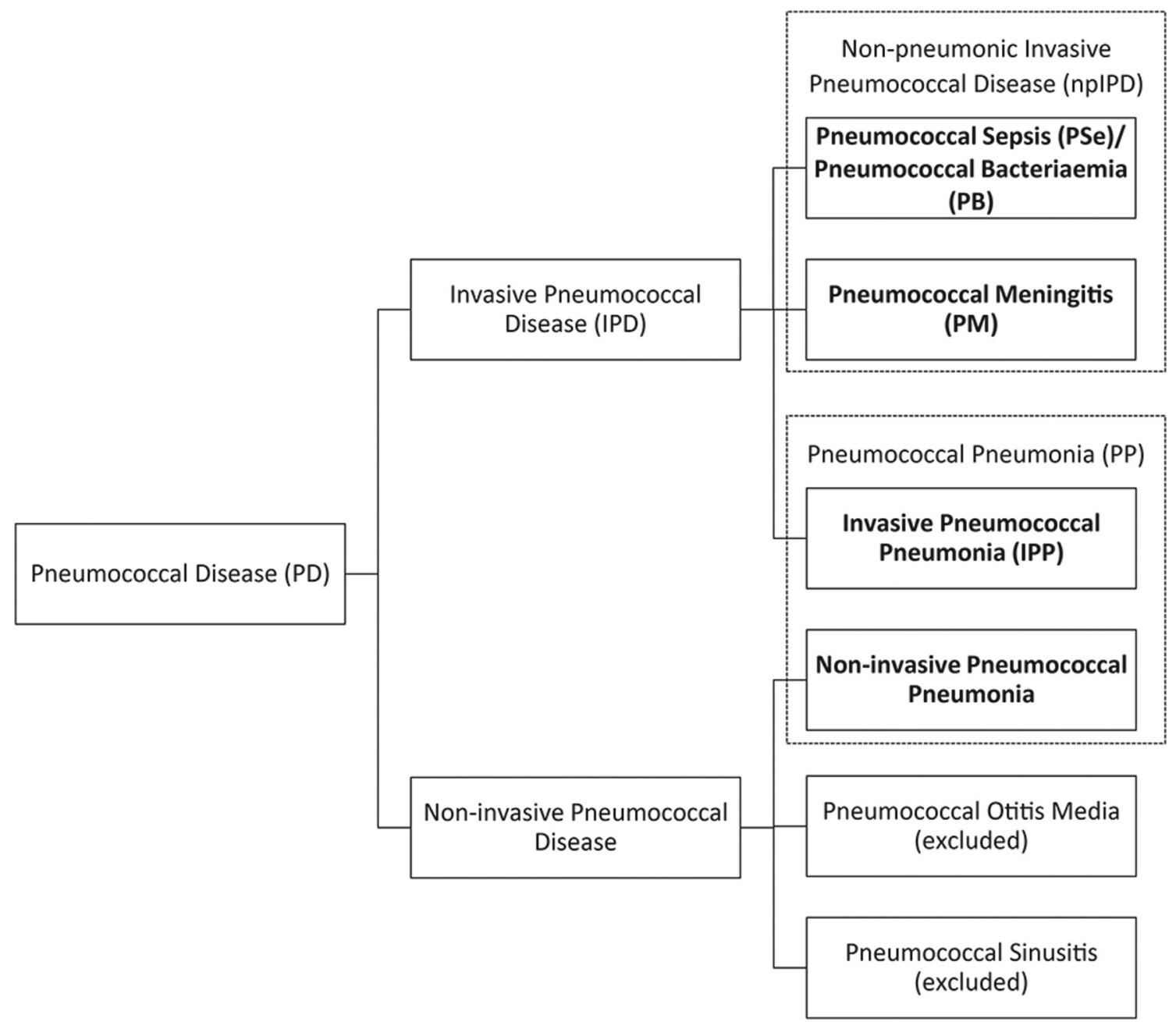

Figure 2 Category of pneumococcal disease in the present review.

cohort studies (online supplementary File S1). The review was conducted and reported according to the PRISMA guidelines (online supplementary File S2). The protocol for this systematic review was registered on PROSPERO (registration number: CRD42017064760; online supplementary File S3).

\section{Definition of PD}

We defined PD as any disease caused by Streptococcus pneumoniae (pneumococcus). Since this definition contains a broad range of diseases and symptoms, including some that are trivial to our review, we adopted a narrower definition. This narrowed definition includes invasive pneumococcal disease (IPD) and pneumococcal pneumonia (PP). We defined IPD as detection of pneumococcus in typical sterile sites (eg, blood, pleural and cerebrospinal fluid). A detailed category of PD for our review is displayed in figure 2. Additionally, we used the term 'non-pneumonic invasive pneumococcal disease (npIPD)', which referred to all IPD without diagnosis of pneumonia, in order to differentiate from both invasive and non-invasive PP.

\section{Definition of VARI}

We defined VARI as a respiratory tract infection with viral aetiology. ILI was viewed as a proxy for influenza infection in the present review. We defined ILI as a symptomatic cough and fever $\geq 38^{\circ} \mathrm{C}$ with onset within 7 days.

\section{Data extraction}

We used a standardised data extraction template to extract relevant data from the eligible full-text studies, including study design, data source, methods, results and conclusion. The principle summary measures of the association between VARI and PD include correlation coefficients, risk ratios, rate ratios, ORs and attributable percentage of PD to VARI. YL and MP independently extracted the data. HN or HC arbitrated any disagreement with the extraction.

\section{Data analysis}

Since it was expected that methodology would differ substantially between studies and a quantitative meta-analysis would not be appropriate, a narrative synthesis was conducted. Studies were summarised according to methodology to allow for more appropriate comparisons of the results.

In addition, because of the concern of multiple testing, we determined the number of tests conducted in each study, so a Bonferroni correction could be applied where applicable; only the tests relevant to the association 


\begin{tabular}{|c|c|c|c|c|c|c|}
\hline Study & $\begin{array}{l}\text { Study } \\
\text { period }\end{array}$ & Population & VARI & $\begin{array}{l}\text { PD (cases } \\
(n))\end{array}$ & Methods & Main findings \\
\hline
\end{tabular}

d, day(s); IFV, influenza virus; ILI, influenza-like illness; IPD, invasive pneumococcal disease; PD, pneumococcal disease; PP, pneumococcal pneumonia; RSV, respiratory syncytial virus; VARI, viral acute respiratory infection; w, week(s); y, year(s).

between VARI and pneumococcal infection were included as part of the correction. The Bonferroni-adjusted significance level was calculated as 0.05 divided by the number of relevant statistical tests within a study.

\section{Patient and public involvement}

No patients or public were involved in the present study.

\section{RESULTS}

A total of 28 studies $^{11-38}$ were eligible and included in the review. We noticed a variety of study designs, exposures and outcomes of interest and analytical methods in these studies (summarised in online supplementary Table S2). Due to the variety, we summarised the studies and displayed the results according to study design and methods.

\section{Individual patient data-based studies}

Individual patient data-based studies during the interpandemic period are sparse. Only three studies ${ }^{1725}{ }^{17}$ were identified (table 1), including two cohort studies ${ }^{17}{ }^{29}$ and one small case-control study by O'Brien $e t a l .^{25}$ The reported results consistently supported the role of preceding VARI on the occurrence of PD. However, the two cohort studies did not attempt to control the seasonal risk factors of VARI and PD that could potentially bias the estimated effect size.

\section{ECOLOGICAL STUDIES}

In our review, $25^{11-16} 18-24$ 26-28 30-38 of the 28 studies were ecological studies. $16^{11} 1314161819$ 21-24 26 32-38 out of the 25 ecological studies controlled for seasonal patterns of VARI and PD (online supplementary Table S2). Additionally, the study by Stensballe $e t a l^{29}$ analysed data at both population and individual levels but did not control for the seasonal patterns.

\section{Correlation analyses with no control for seasonal patterns}

Table 2 shows a summary of 11 studies ${ }^{12-14} 2021232427293033$ using correlation analyses without controlling for seasonal patterns of VARI and PD. Since all studies conducted multiple tests in analysing the correlation (eg, across age groups, viruses and lag time between VARI and PD), the Bonferroni method was applied to adjust the significance level. The correlation between PD and influenza or RSV was statistically significant in all five studies ${ }^{14232429} 30$ that analysed population data of all ages (correlation coefficient r: $0.40-0.71$ for influenza at no time lag, $0.47-0.77$ for RSV at no time lag).

\section{Regression analyses controlling for seasonal patterns}

Table 3 shows the summary of the 15 studies $^{11} 13141618$ 22-24 26 32 34-38 that controlled for seasonal patterns by regression analysis. Results were inconsistent among the studies. In all-age population studies, preceding influenza infection was likely to be associated with IPD (12 studies $^{13} 141618$ 22-24 32 35-38 reported an association and two studies ${ }^{11}{ }^{34}$ reported no association). According to two studies ${ }^{23}{ }^{24}$ that reported age-stratified results, the association between influenza and IPD was more likely to exist among older people than among young children. In terms of preceding RSV infection, four ${ }^{14} 243437$ out of five

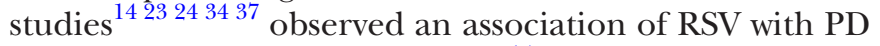
incidence. Specifically, one study ${ }^{14}$ found the association between RSV and IPD only existed among children $<5$ years. Studies reporting other viruses such as ADV and PIV were sparse (two ${ }^{14} 23$ and one $e^{23}$ studies, respectively). Five studies ${ }^{1423} 243437$ that reported two or more viruses demonstrated that the association differed by the type of 


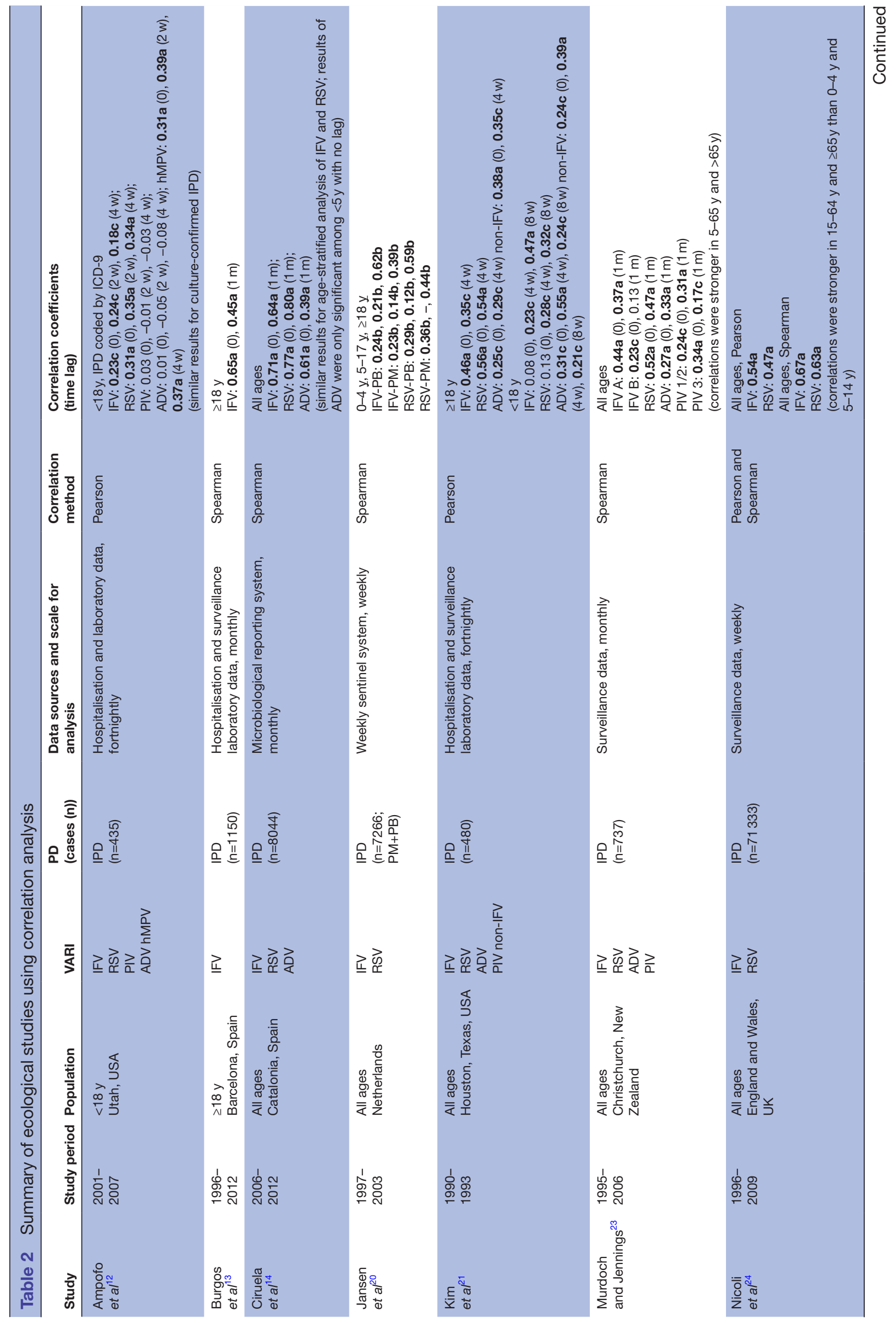

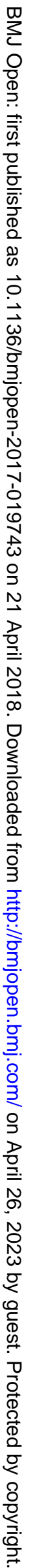



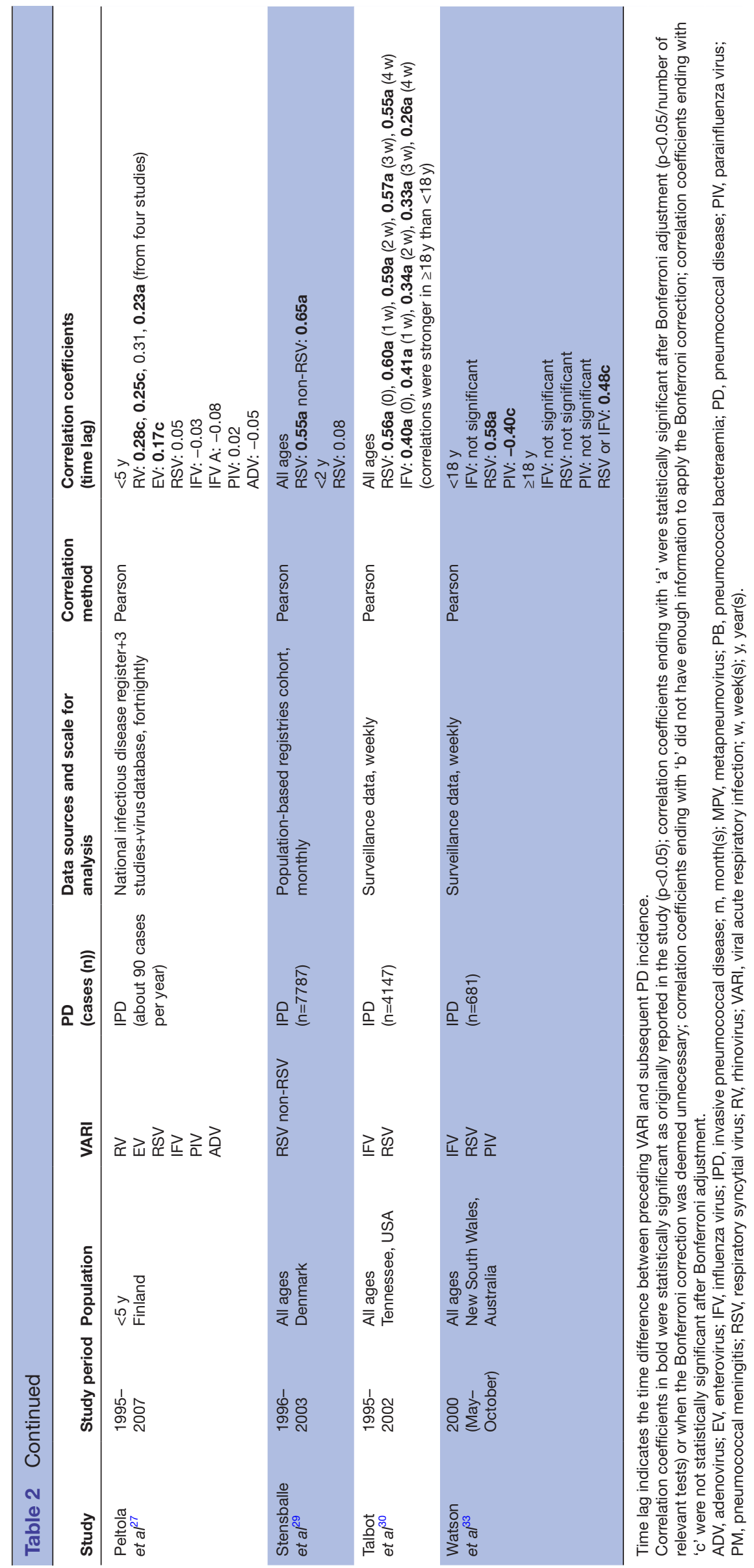

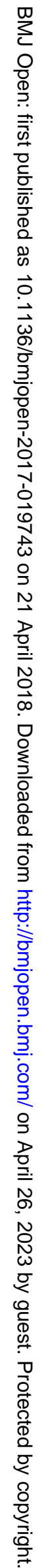




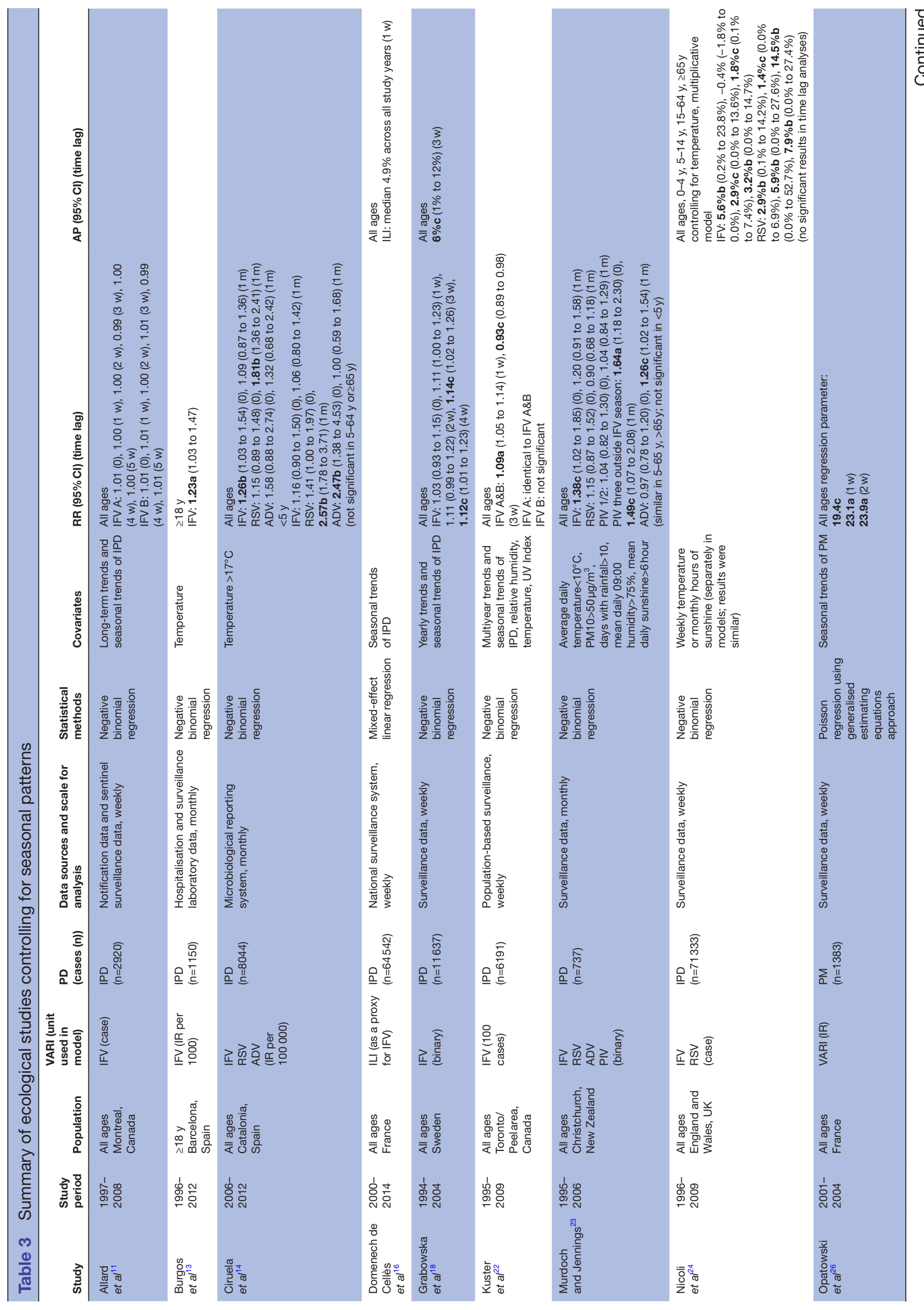

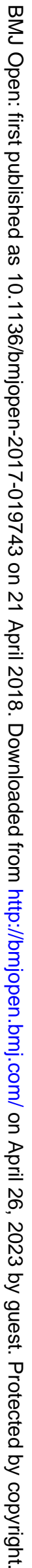




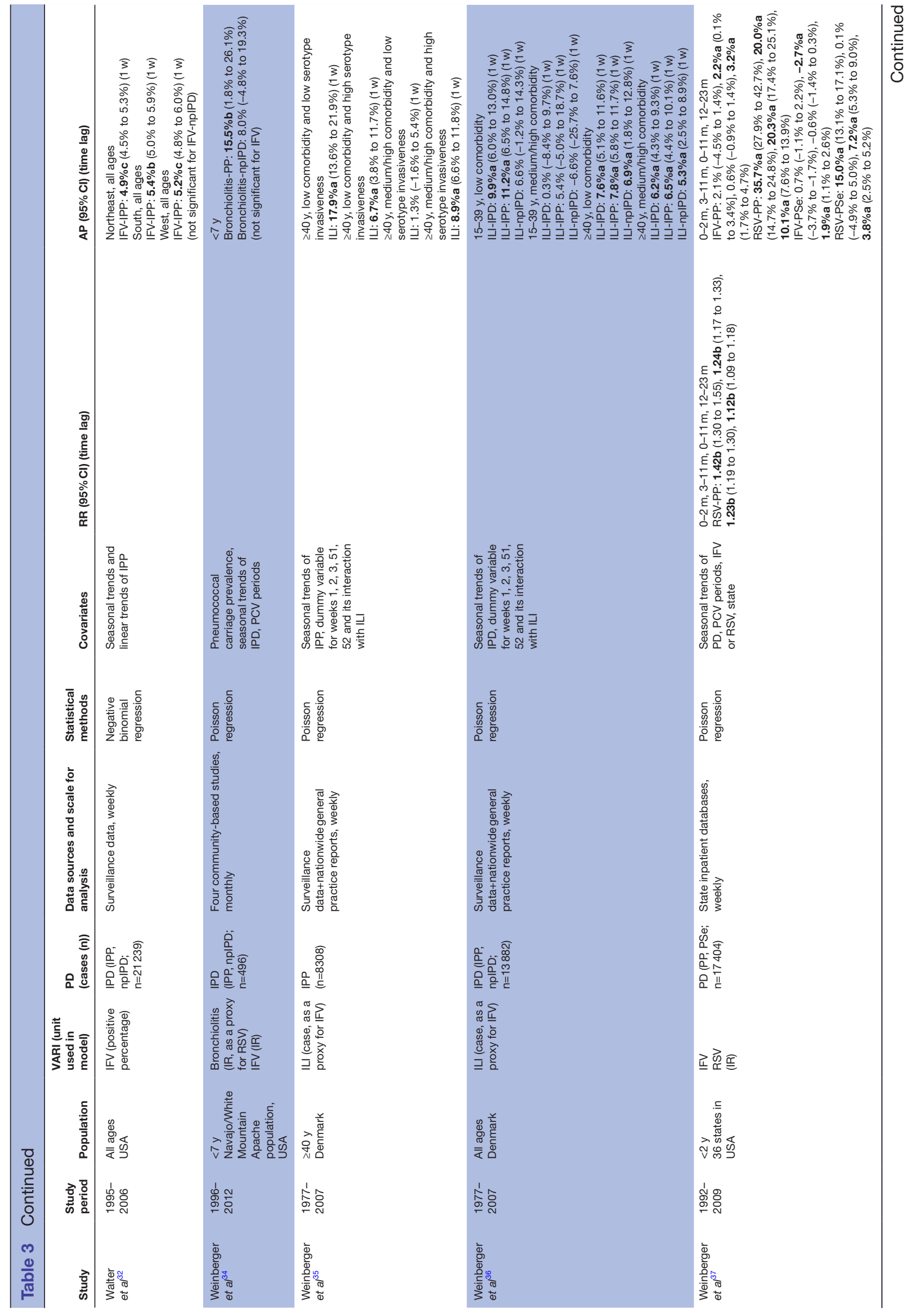


virus. Moreover, the association could differ among virus subtypes (eg, influenza A vs influenza $\mathrm{B}^{22}$ and PIV $1 / 2$ vs PIV 3. ${ }^{23}$ Notably, there are other factors that could influence the strength of the associations reported in these studies. For instance, the association could vary by presentation of PD (invasive PP, IPP vs npIPD ${ }^{32} 3436$ and PP vs pneumococcal sepsis (PSe) $)^{37}$; preceding VARI was more likely to be associated with the occurrence of pneumonia than other clinical presentations. Additionally, the results from studies in Denmark, where comorbidity status and pneumococcal serotype were available, demonstrated that influenza had a greater influence on the incidence of low-invasiveness serotypes than medium or high invasiveness among the low comorbidity group; among the high comorbidity group, the pattern was reversed. ${ }^{35} 36$

Studies using other analyses

Seven ecological studies ${ }^{15} 161922262831$ used other analytical methods (table 4). Except for studies by Hendriks $e t$ $a l^{19}$ and Toschke et $a l^{31}$ all studies reported an association between VARI and PD.

\section{DISCUSSION}

In our review, we summarised population-based studies that evaluated the association of seasonal VARI and subsequent PD. To our knowledge, this is the first review that summarises the methodology and findings of existing epidemiological studies on this topic.

We found that reported associations between VARI and subsequent PD were inconsistent among the 28 included studies. Only three studies ${ }^{172529}$ analysed the association using individual patient data. The two cohort studies ${ }^{17} 29$ did not account for the shared risk factors between VARI and PD that influenced their seasonality, substantially limiting the inferences that can be made from these data while the case-control study ${ }^{25}$ was limited by its small sample size (n case $=13$ ). In ecological studies, only $16^{11} 131416181922-24263234-38$ of the 25 $5^{11-16} 18-2426-2830-38$ ecological studies accounted for seasonal patterns. In these studies, we found that influenza and/or RSV infections were likely to be associated with the subsequent occurrence of PD. For influenza, the association was stronger among younger populations compared with older adults ${ }^{23} 24$ while the pattern was reversed for RSV. ${ }^{14}$ Data from multiple studies suggested that virus type (five studies) ${ }^{1423243437}$ and subtype (two studies) ${ }^{2223}$, comorbidity status (two studies) ${ }^{3536}$ and pneumococcal serotype invasiveness (one study) ${ }^{35}$ could influence the association. However, these 16 ecological studies had various population characteristics (eg, age, comorbidity, immunity status), PD datasets, VARI datasets and analytical methods. As such, heterogeneity among the studies, along with their ecological nature, limits the amount of valid inferences that can be made from the data (as summarised above).

Nevertheless, these studies provide important clues for the potential factors related to the association between 
Table 4 Summary of ecological studies using other methods

\begin{tabular}{|c|c|c|c|c|c|c|}
\hline Study & $\begin{array}{l}\text { Study } \\
\text { period }\end{array}$ & Population & VARI & $\begin{array}{l}\text { PD } \\
(\text { cases (n)) }\end{array}$ & $\begin{array}{l}\text { Data sources and } \\
\text { scale for analysis }\end{array}$ & Methods \\
\hline $\begin{array}{l}\text { Dangor } \\
\text { et } a l^{15}\end{array}$ & 2005-2008 & $\begin{array}{l}<15 \mathrm{y} \\
\text { Soweto, } \\
\text { South Africa }\end{array}$ & IFV & $\begin{array}{l}\text { IPD } \\
(n=636)\end{array}$ & $\begin{array}{l}\text { Hospitalisation } \\
\text { and surveillance } \\
\text { laboratory data, } \\
\text { monthly }\end{array}$ & $\begin{array}{l}\mathrm{X}-11 \text { seasonal } \\
\text { adjustment method } \\
\text { to retain seasonal } \\
\text { components. Peak } \\
\text { timing compared by } \\
\text { time series graph. }\end{array}$ \\
\hline $\begin{array}{l}\text { Domenech } \\
\text { de Cellès } \\
\text { et } \text { al }^{16}\end{array}$ & & $\begin{array}{l}\text { All ages } \\
\text { France }\end{array}$ & $\begin{array}{l}\text { ILI (as } \\
\text { a proxy } \\
\text { for IFV) }\end{array}$ & $\begin{array}{l}\text { IPD } \\
(\mathrm{n}=64542)\end{array}$ & $\begin{array}{l}\text { National surveillance } \\
\text { system, weekly }\end{array}$ & $\begin{array}{l}\text { Correlation analysis } \\
\text { of waveforms of ILI } \\
\text { and IPD }\end{array}$ \\
\hline
\end{tabular}

\begin{tabular}{|c|c|c|c|c|c|c|}
\hline $\begin{array}{l}\text { Hendriks } \\
\text { et } a l^{19}\end{array}$ & 2004-2014 & $\begin{array}{l}\text { All ages } \\
\text { Netherlands }\end{array}$ & $\begin{array}{l}\text { ILI (as } \\
\text { a proxy } \\
\text { for IFV) }\end{array}$ & $\begin{array}{l}\text { IPD } \\
(n=6572)\end{array}$ & $\begin{array}{l}\text { Surveillance data, } \\
\text { weekly }\end{array}$ & $\begin{array}{l}\text { Cross-correlations } \\
\text { of the time series } \\
\text { model (seasonal } \\
\text { autoregressive } \\
\text { integrated moving } \\
\text { average, SARIMA) } \\
\text { residuals }\end{array}$ \\
\hline
\end{tabular}

$\begin{array}{lllll}\text { Kuster } & 1995-2009 & \text { All ages } & \text { IFV } & \text { IPD } \\ \text { et } \text { a }^{22} & & \text { Toronto/ } \\ & \text { Peel area, } \\ & \text { Canada } & & \\ & & & \\ & & \end{array}$

$(\mathrm{n}=6191)$

Population-based

Spearman correlation Phase and

Peelarea,

surveillance, weekly for phase and

amplitude between

amplitude between

IFV and IPD not

IFV and IPD; Granger correlated; Granger

methods to test

whether influenza

test of IFV causing

predicted

crossover analysis to (1.02 to 1.18 ) at $1 \mathrm{w}$

evaluate short-term lag

associations

\begin{tabular}{|c|c|c|c|c|c|c|c|}
\hline $\begin{array}{l}\text { Opatowsk } \\
\text { et } a^{26}\end{array}$ & 2001-2004 & $\begin{array}{l}\text { All ages } \\
\text { France }\end{array}$ & VARI & $\begin{array}{l}P M \\
(n=1383)\end{array}$ & $\begin{array}{l}\text { Surveillance data, } \\
\text { weekly }\end{array}$ & $\begin{array}{l}\text { Mathematic model } \\
\text { of pneumococcus } \\
\text { transmission, } \\
\text { to estimate } \\
\text { the interaction } \\
\text { parameters between } \\
\text { VARI and PM }\end{array}$ & $\begin{array}{l}\text { Factor of VARI on } \\
\text { pneumococcus } \\
\text { acquisition or } \\
\text { transmissibility: } \\
8.7 \text { ( } 4.6 \text { to } 14.4) \text {; } \\
\text { factor of VARI on } \\
\text { pathogenicity: } \\
92 \text { (28 to } 361 \text { ) }\end{array}$ \\
\hline $\begin{array}{l}\text { Shrestha } \\
\text { et }\left.a\right|^{28}\end{array}$ & 1989-2009 & $\begin{array}{l}\text { All ages } \\
\text { Illinois, USA }\end{array}$ & IFV & $\begin{array}{l}\text { PP } \\
\text { (n not } \\
\text { known) }\end{array}$ & $\begin{array}{l}\text { Hospital data, } \\
\text { weekly } \\
\text { (dataset I from } 1989 \\
\text { to } 1997 \text {, dataset II } \\
\text { from } 2000 \text { to 2013) }\end{array}$ & $\begin{array}{l}\text { Mathematic model } \\
\text { of pneumococcal } \\
\text { pneumonia } \\
\text { (PP) transmission, } \\
\text { to estimate } \\
\text { the interaction } \\
\text { parameters between } \\
\text { VARI and PP }\end{array}$ & $\begin{array}{l}\text { Factor of IFV on } \\
\text { PP susceptibility: } \\
\text { dataset I } \\
115 \text { (70 to } 200) \text {, } \\
\text { dataset II } \\
85 \text { (30 to 160) }\end{array}$ \\
\hline $\begin{array}{l}\text { Toschke } \\
\text { et }\left.a\right|^{31}\end{array}$ & 1997-2003 & $\begin{array}{l}<16 \text { y } \\
\text { Germany }\end{array}$ & IFV A & $\begin{array}{l}\text { IPD } \\
(n=1474)\end{array}$ & $\begin{array}{l}\text { Surveillance data, } \\
\text { monthly }\end{array}$ & $\begin{array}{l}\text { Multivariate } \\
\text { time series analysis } \\
\text { using ' } 3 \text { hour } \\
\text { algorithm', which fit } \\
\text { an autoregressive } \\
\text { Poisson or negative } \\
\text { binomial model to } \\
\text { time series }\end{array}$ & $\begin{array}{l}\text { IFV A season did not } \\
\text { affect IPD season } \\
\text { ( } p=0.49) \text {; IFV A peak } \\
\text { did not precede IPD } \\
\text { peak }\end{array}$ \\
\hline
\end{tabular}

IFV, influenza virus; ILI, influenza-like illness; IPD, invasive pneumococcal disease; PD, pneumococcal disease; PM, pneumococcal meningitis; VARI, viral acute respiratory infection; w, week(s); y, year(s). 
VARI and subsequent PD, and thus could help with the conception and design of future studies. Ideally, in order to understand whether a particular preceding VARI can predispose an individual to $\mathrm{PD}$, a prospective cohort study that monitors each individual for VARI and pneumococcal infection would be used, allowing analyses at both individual and population levels. However, such a design would not be feasible or affordable as inter alia pneumococcal infections are rare. Alternatively, the utilisation of large-scale routine health data and reliable data linkage (through unique individual identifiers) from sources such as surveillance data and hospitalisation datasets may be feasible in many industrialised countries. An example of such data linkage in our review is the study by Stensballe et $a t^{29}$ that linked information from four Danish population-based registries. While the authors conducted individual-level analysis, the results were based on cases tested for both the presence of respiratory viruses and pneumococcal infection. The true number of VARI-associated PD cases is likely to be significantly higher due to incomplete testing of cases; the untested viral-pneumococcal cases could represent a crucial source of selection bias. Community-based active surveillance can likely address the issue of missing cases but such surveillance would be labour intensive and less cost effective to conduct. Another option is a case-control study, which is affordable and practical, but not without its limitations. In addition to challenges in designing such studies, defining the history of VARI is likely to be inaccurate since the timing of viral serology may be less accurate (information bias). ${ }^{27}$ In the case-control study by O'Brien et al, ${ }^{25}$ the authors used influenza-strain specific convalescent serology as evidence for preceding influenza infection. The authors also conducted telephone interviews to investigate ILI history but they did not mention whether interviewers and interviewees were blind to case or control status. Moreover, the value of this case-control study is limited by its very small sample size ( $\mathrm{n}$ case $=13$ ).

Compared with individual patient data-based studies, ecological studies are more feasible, and thus the most common study design included in our review (25/28). However, there are some caveats when interpreting results from ecological studies. First, causality can never be inferred from such studies. Second, the results should be interpreted at a population level and cannot be generalised to the individual level. Since ecological studies used data aggregated into broad categories, the potential biases introduced by the aggregation should be taken into account. For instance, while 16 out of 25 ecological studies used weekly data, others used fortnightly or monthly data. This may lead to misclassification as the time window of the association of VARI on PD susceptibility can be as short as 1 week. ${ }^{39}{ }^{40}$ Moreover, data from different sources in ecological studies should represent the same population.

Apart from the study design, one further challenge of analysing the association is accounting for the influence of seasonal factors of VARI and PD (confounding).
Both VARI and PD have similar seasonal patterns, and thus are likely to correlate as indicated by the correlation results from ecological studies. The increased risk of PD during an epidemic season could be caused by VARI or by seasonal risk factors or by both. In the present review, 11 studies $^{12} 1517202127-3133$ did not attempt to control for seasonal confounders, likely leading to biased estimations of the association. For example, the study by Edwards et $^{\mathrm{al}} \mathrm{l}^{17}$ reported a relative risk as high as 112.5 when not adjusting any seasonal factors. One way to address this problem in such studies would be to match the individuals with the onset timing of pneumococcal infection, keeping the risk of PD comparable between VARI cases and non-VARI cases; for ecological studies, regression analysis adding seasonal terms or climatic factors (such as temperature and humidity), or cross-correlation analysis of time series controlling for seasonal patterns could be considered.

Our review suggests that the association of VARI and subsequent PD could vary by virus type ${ }^{1423243435}$ and even by subtype. ${ }^{22}{ }^{23}$ Studies using combinations of viral infections such as all virus, influenza $+\mathrm{RSV}$, non-influenza, or non-RSV could give biased estimations of the association. However, it is not always practical to analyse the association by virus type. In ecological studies, different types of viruses might cocirculate and thus be highly correlated in incidence, making it difficult to determine the role for each virus. In terms of PD, most studies used IPD as the outcome of interest. However, studies that categorised IPD into IPP and npIPD found that the association was more pronounced in IPP than in npIPD. ${ }^{32}{ }^{34}{ }^{36} \mathrm{~A}$ similar finding, that the association was stronger in PP than PSe, was reported in another study. ${ }^{37}$ These results suggest VARI is more likely to be associated with pneumonic pneumococcal infections than non-pneumonic infections. In our review, we excluded studies using information other than clinical diagnosis as a proxy for PD (eg, prescription data and carriage data). Pneumococcal carriage could have a fundamental role in the transmission and incidence of PD. ${ }^{41}$ In a study analysing the impact of pneumococcal carriage and viral activity, Weinberger $e t a l^{34}$ found nPIPD was associated with carriage prevalence, whereas IPP was associated with bronchiolitis (as a proxy for RSV). The authors also proposed that preceding VARI increased susceptibility but did not enhance transmission (indicated by carriage prevalence) in children. However, more studies are needed to confirm these findings.

The association could also vary by population characteristics. According to two studies that displayed age-stratified results, ${ }^{23}$ the association of influenza and subsequent IPD was more likely to exist among older people than among young children. Studies by Weinberger et $a l^{35} 36$ gauged the association in different comorbidity and pneumococcal serotype groups among Denmark populations. The results showed that influenza had a stronger impact on the incidence of low-invasiveness serotypes than medium or high invasiveness ones in the low comorbidity group, while the pattern reversed in the high 
comorbidity group. Another study that analysed clinical records of 919 patients with PP found that infrequently colonising pneumococcal serotypes were more likely to cause PP after preceding VARI, particularly in patients with immunodeficiency or chronic lung diseases. ${ }^{42}$ These findings suggest the need for future studies to analyse the association by age group, pneumococcal serotype and comorbidity status. Moreover, the recent introduction of pneumococcal vaccines has brought changes in the incidence of serotype-specific $\mathrm{PD},{ }^{43}$ making the association of VARI and PD more complicated to understand. As a result, future studies should consider the possible serotype-specific influence that pneumococcal vaccines have on both individual immunity and herd immunity when analysing the association.

In addition to the factors discussed above, additional factors may influence the estimates of the association. The first is the change over time in the methodology of data collection, including changes in test method or diagnosis, clinical practice and health-seeking behaviour. The second is the possible delay in measurement, which happened most often in passive hospital-based studies. Third, for ecological studies using aggregated data, 'holiday spikes' could occur due to more social gatherings ${ }^{44}$; besides, weekends and holidays might influence timely tests or diagnosis as well as the health-seeking behaviour of patients.

To our knowledge, this is the first review to summarise and critically appraise the methods and results of population-based studies about the association between seasonal VARI and subsequent PD. However, this review is not without its limitations. First, due to a variety of study designs, data sources and analytical methods in the studies included, no meta-analysis was conducted in the review. As such, we were unable to provide a quantitative measure of the association of seasonal VARI and PD. Second, no unpublished data sources were included in the review, which could mean the data reported favours positive associations due to publication bias. Thus, caution should be taken when interpreting the results. Third, we found many studies tended to conduct multiple statistical tests using different subgroups and time periods (eg, age group, virus, time lag between VARI and PD) without specifying the primary study question a priori or making proper statistical adjustments to account for multiple testing. This could give rise to an increased risk of reporting false positive results. In this review, we applied Bonferroni corrections to adjust for the multiple tests where deemed necessary. Since the Bonferroni method is conservative and we are unable to adjust for studies where $p$ values were not given, the adjustment in our review is intended for readers' reference and as caveats for future studies.

Given the substantial burden of VARI across the world, ${ }^{1}$ even a modest association between VARI and subsequent PD could lead to a substantial burden of disease in terms of VARI-related PD cases. If proper antibacterial interventions could be applied to those with higher risk of
PD due to a preceding VARI, subsequent pneumococcal infections could be prevented. The interventions would be more effective/better targeted if we could estimate the risk (ie, the strength of association) according to timing of infection by week/month of a year, age, comorbidity status, virus type and status of immunity. In turn, understanding the association between VARI and subsequent pneumococcal infection can help evaluate the full impact of viral vaccine programmes.

In conclusion, the role of seasonal VARI on subsequent PD incidence remains controversial in population-based studies. Nevertheless, these studies provide valuable information and can help with the conception of future well-designed studies. Future work could explore the association by timing of infection, age, comorbidity status, virus type, pneumococcal serotype and presentation, and thus would identify potentially susceptible populations with VARI for preventive interventions.

Acknowledgements YL was supported by a scholarship from the China Scholarship Council.

Contributors $\mathrm{HN}$ and $\mathrm{HC}$ conceived the study. YL did the literature search, reviewed the articles and drafted the manuscript. YL and MP extracted and analysed the data independently with oversight from HN and HC. MP, HN and HC critically reviewed the manuscript. All authors read and approved the final draft of the manuscript.

Funding This research received no specific grant from any funding agency in the public, commercial or not-for-profit sectors.

Competing interests None declared.

Patient consent Not required.

Provenance and peer review Not commissioned; externally peer reviewed.

Data sharing statement Data extraction sheets are available in the Edinburgh DataShare repository, http://dx.doi.org/10.7488/ds/2047

Open Access This is an Open Access article distributed in accordance with the Creative Commons Attribution Non Commercial (CC BY-NC 4.0) license, which permits others to distribute, remix, adapt, build upon this work non-commercially, and license their derivative works on different terms, provided the original work is properly cited and the use is non-commercial. See: http://creativecommons.org/ licenses/by-nc/4.0/

(C) Article author(s) (or their employer(s) unless otherwise stated in the text of the article) 2018. All rights reserved. No commercial use is permitted unless otherwise expressly granted.

\section{REFERENCES}

1. Wang $H$, Naghavi $M$, Allen $C$, et al. Global, regional, and national life expectancy, all-cause mortality, and cause-specific mortality for 249 causes of death, 1980-2013;2015: a systematic analysis for the Global Burden of Disease Study 2015. The Lancet 2016;388:1459-544.

2. O'Brien KL, Wolfson LJ, Watt JP, et al. Burden of disease caused by Streptococcus pneumoniae in children younger than 5 years: global estimates. Lancet 2009;374:893-902.

3. Drijkoningen JJ, Rohde GG. Pneumococcal infection in adults: burden of disease. Clin Microbiol Infect 2014;20 Suppl 5:45-51.

4. McCullers JA. Insights into the interaction between influenza virus and pneumococcus. Clin Microbiol Rev 2006;19:571-82.

5. Chien YW, Klugman KP, Morens DM. Bacterial pathogens and death during the 1918 influenza pandemic. N Engl J Med 2009;361:2582-3

6. Fleming-Dutra KE, Taylor T, Link-Gelles R, et al. Effect of the 2009 influenza $A(\mathrm{H} 1 \mathrm{~N} 1)$ pandemic on invasive pneumococcal pneumonia. $J$ Infect Dis 2013;207:1135-43.

7. Launes C, García-García JJ, Triviño M, et al. Respiratory viruses, such as $2009 \mathrm{H} 1 \mathrm{~N} 1$ influenza virus, could trigger temporal trends 
in serotypes causing pneumococcal disease. Clin Microbiol Infect 2014;20:01088-90.

8. Nelson GE, Gershman KA, Swerdlow DL, et al. Invasive pneumococcal disease and pandemic (H1N1) 2009, Denver, Colorado, USA. Emerg Infect Dis 2012;18:208-16.

9. Pedro-Botet ML, Burgos J, Luján M, et al. Impact of the 2009 influenza A H1N1 pandemic on invasive pneumococcal disease in adults. Scand J Infect Dis 2014;46:185-92.

10. Weinberger DM, Simonsen L, Jordan R, et al. Impact of the 2009 influenza pandemic on pneumococcal pneumonia hospitalizations in the United States. J Infect Dis 2012;205:458-65.

11. Allard R, Couillard M, Pilon P, et al. Invasive bacterial infections following influenza: a time-series analysis in Montreal, Canada, 19962008. Influenza other respi 2012;6:268-75.

12. Ampofo $\mathrm{K}$, Bender J, Sheng $\mathrm{X}$, et al. Seasonal invasive pneumococcal disease in children: role of preceding respiratory viral infection. Pediatrics 2008;122:229-37.

13. Burgos J, Larrosa MN, Martinez A, et al. Impact of influenza season and environmental factors on the clinical presentation and outcome of invasive pneumococcal disease. Eur J Clin Microbiol Infect Dis 2015:34:177-86.

14. Ciruela P, Broner S, Izquierdo C, et al. Invasive pneumococcal disease rates linked to meteorological factors and respiratory virus circulation (Catalonia, 2006-2012). BMC Public Health 2016;16:400.

15. Dangor Z, Izu A, Moore DP, et al. Temporal association in hospitalizations for tuberculosis, invasive pneumococcal disease and influenza virus illness in South African children. PLoS One 2014;9:e91464.

16. Domenech de Cellès $\mathrm{M}$, Arduin $\mathrm{H}$, Varon $\mathrm{E}$, et al. Characterizing and Comparing the Seasonality of Influenza-Like Illnesses and Invasive Pneumococcal Diseases Using Seasonal Waveforms. Am J Epidemiol 2017.

17. Edwards LJ, Markey PG, Cook HM, et al. The relationship between influenza and invasive pneumococcal disease in the Northern Territory, 2005-2009. Med J Aust 2011;194:207.

18. Grabowska K, Högberg L, Penttinen P, et al. Occurrence of invasive pneumococcal disease and number of excess cases due to influenza. BMC Infect Dis 2006;6:58.

19. Hendriks W, Boshuizen H, Dekkers A, et al. Temporal crosscorrelation between influenza-like illnesses and invasive pneumococcal disease in The Netherlands. Influenza Other Respir Viruses 2017;11:130-7.

20. Jansen AG, Sanders EA, VAN DER Ende A, et al. Invasive pneumococcal and meningococcal disease: association with influenza virus and respiratory syncytial virus activity? Epidemiol Infect 2008;136:1448-54.

21. Kim PE, Musher DM, Glezen WP, et al. Association of invasive pneumococcal disease with season, atmospheric conditions, air pollution, and the isolation of respiratory viruses. Clin Infect Dis 1996;22:100-6.

22. Kuster SP, Tuite AR, Kwong JC, et al. Evaluation of coseasonality of influenza and invasive pneumococcal disease: results from prospective surveillance. PLoS Med 2011;8:e1001042.

23. Murdoch DR, Jennings LC. Association of respiratory virus activity and environmental factors with the incidence of invasive pneumococcal disease. J Infect 2009;58:37-46.

24. Nicoli EJ, Trotter CL, Turner KM, et al. Influenza and RSV make a modest contribution to invasive pneumococcal disease incidence in the UK. J Infect 2013;66:512-20.

25. O'Brien KL, Walters MI, Sellman J, et al. Severe pneumococcal pneumonia in previously healthy children: the role of preceding influenza infection. Clin Infect Dis 2000;30:784-9.

26. Opatowski L, Varon E, Dupont C, et al. Assessing pneumococcal meningitis association with viral respiratory infections and antibiotics: insights from statistical and mathematical models. Proc Biol Sci 2013;280:20130519.

27. Peltola V, Heikkinen T, Ruuskanen O, et al. Temporal association between rhinovirus circulation in the community and invasive pneumococcal disease in children. Pediatr Infect Dis $J$ 2011;30:456-61

28. Shrestha S, Foxman B, Weinberger DM, et al. Identifying the interaction between influenza and pneumococcal pneumonia using incidence data. Sci Transl Med 2013;5:191ra84.

29. Stensballe LG, Hjuler T, Andersen A, et al. Hospitalization for respiratory syncytial virus infection and invasive pneumococcal disease in Danish children aged $<2$ years: a population-based cohort study. Clin Infect Dis 2008;46:1165-71.

30. Talbot TR, Poehling KA, Hartert TV, et al. Seasonality of invasive pneumococcal disease: temporal relation to documented influenza and respiratory syncytial viral circulation. Am J Med 2005;118:285-91.

31. Toschke AM, Arenz S, von Kries R, et al. No temporal association between influenza outbreaks and invasive pneumococcal infections. Arch Dis Child 2008;93:218-20.

32. Walter ND, Taylor TH, Shay DK, et al. Influenza circulation and the burden of invasive pneumococcal pneumonia during a non-pandemic period in the United States. Clin Infect Dis 2010;50:175-83.

33. Watson M, Gilmour R, Menzies R, et al. The association of respiratory viruses, temperature, and other climatic parameters with the incidence of invasive pneumococcal disease in Sydney, Australia Clin Infect Dis 2006;42:211-5.

34. Weinberger DM, Grant LR, Steiner CA, et al. Seasonal drivers of pneumococcal disease incidence: impact of bacterial carriage and viral activity. Clin Infect Dis 2014;58:188-94.

35. Weinberger DM, Harboe ZB, Viboud C, et al. Serotype-specific effect of influenza on adult invasive pneumococcal pneumonia. J Infect Dis 2013:208:1274-80.

36. Weinberger DM, Harboe ZB, Viboud C, et al. Pneumococcal disease seasonality: incidence, severity and the role of influenza activity. Eur Respir J 2014;43:833-41.

37. Weinberger DM, Klugman KP, Steiner CA, et al. Association between respiratory syncytial virus activity and pneumococcal disease in infants: a time series analysis of US hospitalization data. PLoS Med 2015;12:e1001776.

38. Zhou H, Haber M, Ray S, et al. Invasive pneumococcal pneumonia and respiratory virus co-infections. Emerg Infect Dis 2012;18:294-7.

39. McCullers JA, Rehg JE. Lethal synergism between influenza virus and Streptococcus pneumoniae: characterization of a mouse model and the role of platelet-activating factor receptor. $J$ Infect Dis 2002;186:341-50.

40. Sun K, Metzger DW. Inhibition of pulmonary antibacterial defense by interferon-gamma during recovery from influenza infection. Nat Med 2008;14:558-64.

41. Simell B, Auranen K, Käyhty $\mathrm{H}$, et al. The fundamental link between pneumococcal carriage and disease. Expert Rev Vaccines 2012;11:841-55.

42. Song JY, Nahm MH, Cheong $\mathrm{HJ}$, et al. Impact of preceding flu-like illness on the serotype distribution of pneumococcal pneumonia. PLoS One 2014;9:e93477.

43. Shiri T, Datta S, Madan J, et al. Indirect effects of childhood pneumococcal conjugate vaccination on invasive pneumococcal disease: a systematic review and meta-analysis. Lancet Glob Health 2017; 5:e51-e59.

44. Walter ND, Taylor TH, Dowell SF, et al. Holiday spikes in pneumococcal disease among older adults. N Engl J Med 2009;361:2584-5. 